\title{
Liminaire Une éthique de la différence raciale
}

\author{
Barbara Godard
}

Liminaires, certainement ces mots écrits dans l'entre-deux du procès discursif où se négotie l'échange des fictions de l'identitaire dans le marché symbolique de "la nation." Lesquels sonts les discours "propres" au Canada? Les manchettes des journaux ponctuent les tournées. Le tour de la clause Canada produit un nouvel accord constitutionnel: la confédération, l'union de dix provinces. Du Québéc, Lise Bissonnette réplique NON. La confédération, n'est-ce pas, est un pacte entre deux "nations fondatrices," entre des "français indigènes" et les "anglais conquérants." Ovide Mercredi proteste des négotiations sécrètes qui risquent d'éliminer les provisions déjà établies pour l'autodétérmination des "premières nations." Cette fiction, stratégiquement essentialiste, affirme la présence continue des amérindiens au pays avant l'arrivé des colons européens.

Il y a beaucoup en jeu: qu'est-ce que le sujet "Canadien"? Quelles seront les formes culturelle(s) et linguistique(s) pour légitimer son identité en tant que sujet? Au profit de qui la figuration symbolique? Lesquelles catégories, lesquelles modes de classification, vont l'ordonner? L'accès au capital symbolique, et ainsi aux pouvoirs politique et économique, est en jeu dans ce différend de figuration du sujet "national." La représentation implique la production d'une valeur d'échange dans une économie symbolique spécifique. Des représentations, produisant des effets du réel, ont ainsi des conséquences politiques. Actuellement, le concept d'une nation-état (une abstraction neutre fondée sur la fiction d'un impératif géographique, voire régionaliste) s'oppose à des versions d'une nation-culture (fondées toutes les deux sur des fictions d'une pureté ethnique et un impératif temporel d'antériorité). Ces fictions d'un peuple "de souche" divergent, cependant, dans leurs figurations de la relation avec l'espace, le "nomadisme" où le déploiement dans l'espace de l'amérindien s'opposant au "squatter" français que développe un petit terrain en vue de l'avenir (Jasmin). 


\section{Tessera}

La question du genre du sujet a étéécarté, dans cette concurrence pour faire valoir les droits au nom "Canadien," et les fictions de l'identitaire de ce sujet légitimées par les institutions politique et culturelle. C'est un sujet masculin qui est produit par ce projet constitutionnel constatent des groupes féministes qui dénoncent le projet comme un recul par rapport à la reconnaissance de l'égalité entres les sexes dans l'article 28 de la Constitution de 1982. Un recul aussi, par rapport aux ententes informelles prises au printemps dernier dans des forums publiques sur le principe de l'égalité des sexes à être inscrite dans la composition du Sénat Triple-E. Parmi ces groupes, le Native Women's Association (L'Association des femmes autochtones), appuyé par le National Organization of Immigrant and Visible Minority Women (l'Organisation nationale des femmes immigrantes et des minorités visibles) et le Comité Canadien d'Action sur le Statut de la Femme, a fortement critiqué le projet constitutionnel. Ces féministes protestent le principe d'auto-détermination pour les autochtones qui va être investi dans des gouvernements dominés par des hommes, en contradiction avec le pouvoir politique traditionnel des femmes autochtones, des gouvernements qui seront dispensés spécifiquement des articles de la Charte des droits et libertés protègeant l'égalité des femmes. Ce différend des fictions de l'identitaire, chacune avec un protocol différent pour régler l'accès aux ressources rares - la terre, la langue et d'autres formes symboliques, le pouvoir, en bref - monopolise les pages d'information des journaux tandis que dans les éditions du dimanche, parmi les faits divers, on peut lire que la proportion des minorités visibles parmi la population de Toronto va atteindre $45 \%$ par l'an 2001. ("The Minority Report", Toronto Star, 7 June 1992).

Le visage du Canada change, rapidement même, dans un sens que le débat constitutionnel ne reconnaît pas. Est-ce que ce regard autre s'accompagne d'une manière de regarder autrement? Le binaire information/fait divers semble dire que non. Ce binaire accordel'effet du réel aux représentations de la nation-état, tandis qu'il place du côté de l'imaginaire (et masque, ainsi) les instances du racisme quotidien. Ce genre de camouflage (re)produit le racisme. Les institutions qui règlent les valeurs symboliques ne changent pas vite. N'y a-il pas d'autres lieux d'où émerge un regard nouveau sur les questions de la terre, la langue et la culture? Est-ce qu'ily a deséconomies du regard altérnatives qui pourront s'exercer sur l'ordre symbolique, et ainsi, sur l'accés au capital culturel et économique? Est-ce que regarder autrement fait la (une) 
différence? Est-ce que ces regards autres puissent tenir compte des différences complexes de race et de sexe? Est-ce possible de dépasser l'analogie téléscopique "femme/indigène/autre" (bien que la tentation s'accroît dans le contexte du récit du débat constitutionnel où la femme indigène figure la résistance) pour analyser la surdétermination de leur intersection, en lisant des théories et des textes spécifiques pour leurs non-dits et pour leurs contradictions?

L'autre regard/Other Looks soulêve ce défi d'un regard autre. Les textes explorent de manières diverses l'inscription des femmes des races et d'ethnies marginalisés par l'institution littéraire canadienne/québécoise. En tant que minorités "visibles," elles ont l'aspect différent et ainsi posent avec force la question de la représentation, fondé sur une économie du même, de la mimésis. Cependant, ces minorités ont été "invisibles," étant donné les pratiques ordinaires des cultures canadienne et québécoise qui "font semblant," qui nient la différence pour ainsi faire la cohésion en produisant du même. Ce sont les femmes de ces communautés minoritaires qui, par leurs regards critiques, ont souligné l'ethnocentrisme de la société dominante, y compris des théories féministes. Les projets et les protocols d'adresse propre au féminisme fonctionnent comme des barrières invisibles dont les effets d'exclusion sont ressentis par celles qui ne partagent pas le point de vue commun.

Une des critiques majeures s'adresse à la priorité accordée dans la problématique féministe à la différence sexuelle, une question qui pose l'égalité (ou la différence) avec les hommes comme la question principale pour le féminisme, une problématique réglée par le binaire homme/femme. Pour des femmes des ethnies et des races minoritaires, la question de l'appartenance au groupe culturel est une problématique aussi pertinente pour elles car la société canadienne/québécoise s'organise autour de le race comme une marque de distinction sociale. On accorde plus de capital symbolique aux "blancs" qu'aux gens de "couleur". Ainsi, cette question supplémentaire au féminisme devient une question de la plus grande importance pour les femmes des groupes minoritaires qui sont impliquées dans plusieures formes d'oppression. "De la marge au centre," écrit bell hooks. Avec leur persistance, elles ont changé la question, transformé la problématique du féminisme pour l'orienter autour des rapports femmes/femme. Comment la catégorie de "femme" a-t'elle servi les buts du phallogocentrisme, empêchant un ordre symbolique autre où les femmes échangeront des valeurs entre elles, y compris celle de la différence incommensurable? Ainsi, poser la 


\section{Tessera}

question du rapport du genre et de la race à la représentation exige un changement de modèles et de méthodes - non plus un ordre fondé sur les binaires et la substitution mais sur des différences relationelles, ordonnées par la combinaison ou la superposition. Car l'enchêvetrement des oppressions de la race, de l'ethnie, de la classe, de l'orientation sexuelle et du genre, est à la fois complexe et spécifique à une instance historique. Les groupes ne sont pas unifiés, ni les conditions homogènes. On aborde ici l'espace d'une culture incertaine.

Les texte théoriques réunies dans L'autre regard/Other Looks essaient délaborer des approches qui favorisent le contradictoire, le contaminé, l'hétérogène, plutôt que les distinctions nettes, la pureté. Aucune des essayistes n'emploie la terminologie courrante du "multiculturalisme," "le transculturel," ou "l'interculturel," cependant. Ces concepts ont tous été critiqués pour l'uni-directionalité de leur modélisation des transferts culturels, leur eurocentrisme. Les critiques féministes ici contournent ces débats pour cerner la problématique de la complexité des relations et de la mobilité du champ d'analyse - le centre et la périphérie se déplacent au fur et mésure que l'on les cerne. Lucie Lequin et Maïr Verthuy font $l^{\prime}$ historique du mythe fondateur monolithique et ethnocentrique des québécois, qui produit l'(im)migrante comme l'autre marginalisée, pour analyser ensuite l'ouverture, la mobilité, la rupture, effectuée par des écrivaines métissées de provenance diverse pour qui l'errance et l'écriture sont les voies d'un projet identitaire, les voix de l'auto-création. Tout comme Christl Verduyn, Verthuy et Lequin centrent leur analyse sur l'oeuvre spécifique d'une seule écrivaine, Nadine Ltaif et Mona Latif Ghattas respectivement. Leslie Sanders adopte une approche semblable pour retracer la théorie de la différence sexuelle et raciale telle qu'élaborée par Marlene Nourbese Philip (originaire des Caribbes) dont l'importance accordé à l'espace entre - entre cultures et races, entre les jambes de la femme - est l'espace de la création et de la libération radicale à la fois de l'impérialisme de l'esclavage et des récits de la décolonisation écrits dans un langage neutre qui efface le féminin. Avec la "jammette," elle joue à brouillir les codes, les frontières.

Dans son entretien avec Janice Williamson, l'écrivaine Okanagane Jeannette Armstrong aborde cette question pour élaborer d'abord son esthétique qui emprunte de la philosophie traditionnelle des amérindiens une importance première à la puissance féminine. Ensuite, pour diffuser cette pensée autre, elle parle de la necessité d'établir des rapports, de créer des lecteurs/lectrices par le développment d'une 
institution autochtone indépendante avec une presse (Theytus), un collège avec un programme d'études orienté sur la culture des autochtones ayant des cours en création littéraire (En'owkin International School of Writing) où l'on étudie l'art oratoire traditionnel en rapport avec les stratégèmes d'écriture y compris les formes pour écrire des comptes-rendu des oeuvres des autochtones. Armstrong soulève ici la question ponctuelle de l'institution littéraire, celle de la récuperation. Mais elle n'en parle pas dans les termes essentialistes et desuètes de la culture comme la proprieté, mais en orientant le débat sur l'accès des autochtones, avec leur regard autre, au marché des biens littéraires et symboliques. Armstrong souligne la necessité de faire des ponts, pour établir des dialogues entre cultures, entre langues.

Luanne Armstrong aborde ce dialogue de l'autre versant, comme une professeure blanche dans un collège où les étudiant-e-s sont des autochtones. Elle soulève la question inverse de la responsablité de celles du côté du pouvoir. Elle démontre la necessité pour, et analyse le chemin pénible d'une auto-analyse de la blancheur de blanc. Qu'est-ce que cela veut dire "être blanc-he"? Quels privilèges sont accordés aux blanc-he-s par le teint de leurs peaux? Comment est-ce que l'on peut minimiser les effets négatifs de ce pouvoir? Comment libérer l'espace de/pour l'autre? Ce genre d'interrogation du pouvoir par celles qui en jouissent de ces privilèges est nécessaire avant que le changement se fasse.

La douleur est le mot clé de Busejé Bailey, associée à l'esclavage qui a été pour cinq cents ans l'histoire des Afro-canadiennes. Si grande a été la blessure, que ce malheur n'a jamais été redressé ni même adressé. Certain-e-s Afro-canadien-ne-s émancipé-e-s interdisent même de penser de l'esclavage, elle suggère, s'approchant ainsi de la position de Nourbese Philip. Dans ses images "Body Politic" Bailey expose la souffrance marquée dans les corps mêmes des femmes noires, leur peau le signifiant dans le discours de la race. D'un côté elle explore le travail de la répresentation qui code les couleurs sur le marché symbolique. "Black label," un titre ironique, pèse le noir chic de la bière contre le noir méprimé des femmes noires absentes de l'image, invisibles. De l'autre, elle expose la peau/écrin, "skin/screen," tatotuée par des slogans racistes, l'espace intime de la femme noire submis à la violence des discours dominants.

Les textes de création déploient toutes les valences de la syntaxe de l'ethnicité. Explorant le dilemme de vivre entre deux espaces, deux langues, deux cultures, l'écriture des migrantes oscille entre la nostalgie 
d'un pays à reprendre par la mémoire et la colère d'une place, d'une intervention à faire dans le nouveau pays par la dissidence. C'est-à-dire, l'oscillation entre une syntaxe de retention et une de restitution. Par la superposition des pays et des langues, une vision stéréoscopique qui produit du dérangement, du nouveau, trois écrivaines d'origine arabe de pays divers - l'Egypte, le Liban et l'Algérie - font un retour par la mémoire au vieux pays pour rejeter ensuite la tentation de répéter toujours la même histoire. Pour elles, la traversée de la mer, l'ambiguité d'une nouvelle langue, produit une rupture qui ne peut être comblé que dans l'écriture. D'ailleurs, elles viennent de familles déjà en errance. Sachant dans un monde contingent que les maisons sont provisoires, construites, l'exile passe sa vie à créer un monde. En conséquence, vécrire devient l'unique mode du présent, un processus pour relier le passé et le futur.

Mona Latif Ghattas explore surtout le silence qui enveloppe les êtres chères - la grand'mère - laissé-e-s dans le vieux pays perçu-e-s à travers les non-dits de(s) l'histoire(s). Le "je" écrivant est à la dérive, ne trouvant pas le "tu" d'un-e narrataire. Mais la dislocation du récit pourrait produire quelque chose au-délà de la mémoire d'un acte manqué. Une promesse seulement. Nadine Ltaif écrit du problème d'être toujours l'étrangère, la folle, l'être divisée en exile “à l'ombre d'Hécate." Mais le double regard ainsi fourni pourrait être transformé en auto-affirmation par la transition du fluide, du mobile de la mer/mère. Ces notes provisoires inscrivent cette être nouvelle. Nadia Ghalem trace le processus de l'auto-création en invoquant un troisième lieu, Paris, comme l'espace entre, pour sortir du système topographique binaire de la migrante. Ce texte prévoit une transformation à l'avenir par la re-mémorisation et le réalignement du passé. Paris (le Musée Cluny) réunit tous les temps, tous les espaces. La narratrice re-voiel'histoire et se souvient des femmes chefs en Afrique du nord autrefois. Elle retrouve des amies d'enfance exilée d'Algérie par une société patriarcale. Dans le passé, l'Algérie a acceuilli les peuples de plusieures vagues de migrations. Ce souvenir d'une nation d'ethnies hétèrogènes lui permet d'habiter dans son imagination Montréal avec sa population aussi diverse. La litanie des noms du pays familiers est une répétition par où ces écrivaines retrouvent ou remplacent la mère archaïque dans une confrontation ambigue et perpetuelle avec elle (Kristeva 291). Le sujet remémorisant se situe dans l'imaginaire, dans l'abjection avant la séparation du sujet et de l'objet. À travers la voile de la mémoire, la topographie de la maison devient 
"unheimliche," inconnue, étrangère.

Les textes de Leila Sujir et Suniti Namjoshi, originaires de l'Inde, adopte une autre syntaxe, celle de "l'invention d'un syncrétisme" (Sekyi-Otu 194-7). Elles déploient l'humour, la parodie, dans une syntaxe de l'excès, pour faire une disjonction entre le sujet et l'objet et produire des nouvelles orientations. Travaillant des frontières perméables, l'esprit s'engage dans un jeu du différent dans le semblable et du semblable dans le différent pour se concentrer sur l'écart. L'aspect carnivalesque s'annonce dans l'angle de vision, celui de l'enfant chez Namjoshi, celui de l'aubergine-oiseau chez Sujir, pour défamiliariser le topos mythique et la topographie familière des plaines d'Alberta en les rendant risibles. Elles écrivent des fables toutes les deux. Namjoshi récrit le mythe impérialiste et patriarcal du Saint George et le dragon. Une sainte en devenir, avec un prénom indien, Suniti, se rivale avec le protecteur d'Angleterre, avec une différence. Car elle assiste à la naissance des petits dragons et reconforte le dragon mourrant. Cet acte qui protège les citoyens n'est recompensé que d'une pomme. Le fable souligne en conclusion les problèmes pour une étrangère qui suit des règles différentes d'être valorisé par le pouvoir. Sujir écrit un texte surréal, une rêve de la mère qui survole le terrain et imagine la transformation de l'ordre social par les nettoyeurs de nuit, les sousprivilègiés de classe et de race, les gens qui nettoyent non seulement les grands immeubles mais aussi les cauchemars del'histoire qui oppriment tantles gens aux peaux foncées, soit en exile dans la diaspora soit assiégés chez eux où le rêve mal à propos de Columbus les a déplacé. La mère imagine une nouvelle histoire, sans clôture, une histoire qui ne confinera plus ces gens ni déformera leurs représentations. Ils seront appelés des aubergines, une légume noire et reluisante, de teints très variés. Des différences aussi parmi les "gens de couleur" qui sont nullement homogènes.

"Maquillants" des visages. Construisants des images. Avecl'humour elles font des grimaces, un mimétisme du discours dominant pour s'en prendre à leur lecteurs/lectrices blanc-he-s tout en riant avec elles/eux. Gardant leur distance, quand même. Faisant face. En soulignant ainsi l'artifice de l'aspect, la fabrication de l'optique, elles font face à l'histoire. (Dé)tournent ses pages. Faisant de(s) histoire(s). Regardant autrement. Ainsi elles construisent des fictions provisoires pour être transformées dans/par l'échange. Tous les textes cherchent ainsi à libérer la culture des théories binaires, non pas dans une optique qui vise à abolir " 1 'autre" 
avec le même, comme dans les théories de l'emancipation, mais dans un angle de vision qui pourra tenir compte d'un processus par où la culture circule, produisant des changements, des cultures, par des contact(s) continu(s). 